OPEN ACCESS

Edited by:

Krystyna Pierzchala-Koziec, University of Agriculture in Krakow,

Poland

Reviewed by:

Vincenzo Tufarelli,

University of Bari Aldo Moro, Italy

Ahmed Ali Saleh,

Kafrelsheikh University, Egypt

*Correspondence:

Hui Wang

wanghui19911016@163.com

Hai Lin

hailin@sdau.edu.cn

${ }^{\dagger}$ These authors have contributed equally to this work

Specialty section:

This article was submitted to

Avian Physiology,

a section of the journal

Frontiers in Physiology

Received: 15 July 2019 Accepted: 22 May 2020

Published: 12 June 2020

Citation:

Wang H, Liu S, Li J, Wang L, Wang $X$, Zhao J, Jiao H and Lin H

(2020) 5-Hydroxytryptophan

Suppresses the Abdominal Fat

Deposit and Is Beneficial to the Intestinal Immune Function in Broilers.

Front. Physiol. 11:655

doi: 10.3389/fphys.2020.00655

\section{5-Hydroxytryptophan Suppresses the Abdominal Fat Deposit and Is Beneficial to the Intestinal Immune Function in Broilers}

\author{
Hui Wang ${ }^{1 * t}$, Shaoqiong Liu' ${ }^{2+}$, Jun Li ${ }^{1}$, Liyuan Wang ${ }^{1}$, Xiaojuan Wang ${ }^{1}$, Jingpeng Zhao', \\ Hongchao Jiao ${ }^{1}$ and Hai Lin ${ }^{1 *}$ \\ 1 Shandong Provincial Key Laboratory of Animal Biotechnology and Disease Control and Prevention, Shandong Agricultural \\ University, Tai'an, China, ${ }^{2}$ Key Laboratory of Etiology and Epidemiology of Emerging Infectious Diseases in Universities \\ of Shandong, Shandong First Medical University and Shandong Academy of Medical Sciences, Tai'an, China
}

Background: Serotonin (5-HT), a monoaminergic neurotransmitter, involves in the regulation of many physiological functions. In the present study, the effects of 5hydroxytryptophan (5-HTP), the precursor of 5-HT, on lipid metabolism and intestinal immune function in broiler chickens were investigated in chickens.

Methods: Two hundred broilers were divided randomly into two groups and fed separately with a corn-soybean basal diet (CD) or the basal diet supplemented with $0.2 \% 5-\mathrm{HTP}$.

Results: The results showed that 5-HTP reduced $(P<0.05)$ feed intake and the abdominal fat pad weight. 5-HTP treatment tended to upregulate the mRNA level of adiponectin receptor 1 (ADP1R) and ADP2R in abdominal fat but had no significant influence on their protein levels $(P>0.05)$. In 5-HTP-chickens, lipopolysaccharide exposure decreased secretory immunoglobulin A (slgA) concentrations in serum and the duodenal contents. Expression of mRNA encoding interleukin (IL), tumor necrosis factor$\alpha($ TNF- $\alpha)$, and transforming growth factor- $\beta$ (TGF- $\beta$ ) decreased after 5-HTP treatment; however, LPS increased expression significantly in 5-HTP-treated chickens compared with CD chickens. In 5-HTP-chickens, the phosphorylation of mitogen-activated protein kinase (MAPK) and nuclear factor-kappa B (NF-kB) were reduced, but the phosphorylation of ribosomal p70S6 kinase (p70S6K) was increased in the duodenum.

Conclusion: In summary, the result suggests that dietary 5-HTP supplementation reduces accumulation of abdominal fat and is beneficial to intestinal immune function.

Keywords: 5-hydroxytryptophan, lipid metabolism, intestinal inflammation, LPS, broiler

\section{INTRODUCTION}

Serotonin (5-HT) is a monoaminergic neurotransmitter that modulates the function of the central and peripheral nervous systems (Veenstra-VanderWeele et al., 2000). There are two independent 5-HT systems: the central nervous system and the peripheral system. Central 5-HT is synthesized by tryptophan hydroxylase 2 (TPH2), the rate-limiting enzyme for 5-HT biosynthesis 
(Walther et al., 2003). Peripheral 5-HT is synthesized by intestinal enterochromaffin (EC) cells upon the catalysis by tryptophan hydroxylase 1 (TPH1; Sun et al., 2019). As 5-HT is unable to cross the blood-brain barrier (El-Merahbi et al., 2015) the lack of peripheral or central 5-HT cannot be replaced by the other resource. Once released, 5-HT combines with 5-HT receptors, most of which are G-protein-coupled receptors (except receptor 3, which is a ligand-gated cation channel) (Oh et al., 2015). In chicken and other species, the CNS and peripheral serotonergic systems act independently and meanwhile interact via the blood stream, as affected by hormones (corticosterone, cytokines, enzymes, and short-chain fatty acids), gut microbiota, and vagus nerve activation (de Haas and van der Eijk, 2018).

In rats, peripheral 5-HT changes lipid metabolism by accelerating bile acid turnover (Watanabe et al., 2010). In mice, 5-HT can induce lipogenesis or triglyceride (TG) synthesis in the liver and white adipose tissue (Namkung et al., 2015). Inhibiting peripheral 5-HT synthesis reduces obesity and induces metabolic dysfunction by promoting brown adipose tissue thermogenesis (Crane et al., 2015). In poultry, however, lipid metabolism and its regulatory mechanism are different from those in mammals. The main site of lipid synthesis is the liver and the lipogenesis in adipose tissues is limited (Brady et al., 1976; Bedu et al., 2002). Thus, the effect of 5-HT on lipid metabolism in chickens remains to be elucidated.

The peripheral 5-HT is synthesized in EC cells within the gastrointestinal mucosa and therefore the role of 5-HT on gut immunity gains more attention. 5-HT is an important mucosal signaling molecule, playing vital roles in inflammatory conditions of the gut (Ghia et al., 2009). There is increasing evidence supports the concept that 5 -HT is directly involved in pathological mechanisms, as well as the modulation of immune/inflammatory responses within the gut (Cirillo et al., 2011). 5-HT could enhance the host immune function by inhibiting the production of TNF- $\alpha$ (Perianayagam et al., 2005). Recently, the distinct correlation between 5-HT levels and the occurrence of stress-induced diarrhea was observed in weaning mice, which may result in the deregulation of the mucosal immune system (Dong et al., 2017). In broiler, L-tryptophan supplementation could relieve stress-effected expression of IL1, IL-6, IL-10, and TNF- $\alpha$ by regulating 5-HT metabolism (Yue et al., 2017) and increase serum IgM concentration quadratically in laying hen reared under hot and humid summer conditions (Dong et al., 2012). Except of the behavioral responses, earlylife microbiota transplantation has long-term effects on immune characteristics and peripheral serotonin of chicken in a genotypedependent way (van der Eijk et al., 2020). As the intermediate metabolite of the essential amino acid L-tryptophan in the biosynthesis of 5-HT, 5-Hydroxytryptophan (5-HTP) has been used as a clinically effective serotonin precursor (Birdsall, 1998). 5 -HTP is present at low levels in the nervous system because it is rapidly converted to 5-HT (Sloley and Juorio, 1995). 5HTP is therapeutically used for several psychiatric disorders such as anxiety and depression in the clinic (Murray, 2000; Sahelian, 2000). In broilers, it was reported that there is a possible interaction of 5-HTP and Lactobacillus spp. on the immune system of broiler chickens (Donato et al., 2015). Therefore, we hypothesized that 5-HTP may play a role in intestinal immune function in chickens.

Here, we examined the effect of dietary supplementation of 5HTP on lipid metabolism and intestinal immune function. The transcriptional level of genes related to lipid synthesis in the liver and abdominal fat pad was determined. The concentrations of immunoglobulin A (IgA) and mRNA level of cytokines in the intestinal tract were measured to evaluate the immune function of lipopolysaccharide (LPS)-challenged chickens.

\section{MATERIALS AND METHODS}

The study was approved by Ethics Committee of the Shandong Agricultural University and carried out in accordance with the "Regulations for the Administration of Affairs Concerning Experimental Animals Guidelines" and "Guiding Directive $s$ for Humane Treatment of Laboratory Animals" by the Ministry of Science and Technology (1988a,b). All husbandry practices and euthanasia were performed with full consideration of animal welfare.

\section{Animal Management and Sample Collection}

Two hundred day-old male broilers (Arbor Acres) were obtained from a local hatching farm (Dabao, Taian, China). All the chicks were reared in an environmentally controlled room, and the rearing temperature was maintained at $33^{\circ} \mathrm{C}$ from Day 1 to Day 5 and then gradually reduced, according to normal management practices, to a temperature of $22^{\circ} \mathrm{C}$. Chickens were reared in floor pens $(2 \mathrm{~m} \times 2 \mathrm{~m})$ using rice hulls as litter. Each pen was equipped with tube feeders (the feeder space per bird was $2.5 \mathrm{~cm}$ ) and nipple water-line (12 birds per nipple). The light regimen was 23 L:1 D and the dark period was from 0:00 to 01:00 a.m. (Zhao et al., 2012; Tang et al., 2019).

The experiment started from the Day 8 to let all the broiler chicks adapt the rearing environment (Yassin et al., 2009; Yerpes et al., 2020). All the experimental chicks were fed with a cornsoybean basal diet ( $21 \%$ crude protein) until 7 days of age. Thereafter, the chicks were assigned to eight pens of 25 chicks according to body weight. The eight pens of broilers were randomly divided into two groups composed of four pen each and subjected to one of the two following treatments: fed with the basal diet (CD), or the basal diet supplemented with $0.2 \mathrm{~kg}$ 5-HTP per $100 \mathrm{~kg}$ diet (Donato et al., 2015). The basal diets were formulated according to the growing stage of broilers: the starter diet with $21 \%$ crude protein and $12.6 \mathrm{MJ} / \mathrm{kg}$ metabolizable energy (ME) was fed from 1 to 21 days of age; the grower diet with $19 \%$ crude protein and $13.0 \mathrm{MJ} \mathrm{ME} / \mathrm{kg}$ was fed from 22 to the end of experiment (Table 1; Zhao et al., 2012; Chen et al., 2018). All the broilers had free access to feed and water during the entire experimental period. Body weight (BW) and feed intake (FI) were recorded weekly and the feed conversion ratio (FCR) were calculated.

After 35-day of age, two broilers around mean body weight were randomly selected from each pen, eight broilers in total in each treatment. After overnight feed withdrawal, a blood sample 
TABLE 1 | The composition and nutrient levels of the experimental diets.

\begin{tabular}{|c|c|c|}
\hline Ingredients (\%) & 1-21 days & 21-35 days \\
\hline Corn $(8.5 \% \mathrm{CP})$ & 57.00 & 62.00 \\
\hline Soybean meal (46\% CP) & 34.40 & 29.50 \\
\hline Soya bean oil & 3.90 & 4.50 \\
\hline Dicalcium phosphate & 1.70 & 1.55 \\
\hline L-Limestone & 1.67 & 1.42 \\
\hline Sodium chloride & 0.31 & 0.28 \\
\hline Choline chloride (60\%) & 0.26 & 0.20 \\
\hline L-Lysine $\cdot \mathrm{H}_{2} \mathrm{SO}_{4}(70 \%)$ & 0.02 & - \\
\hline DL-methionine (98.5\%) & 0.49 & 0.30 \\
\hline Vitamin premix ${ }^{*}$ & 0.05 & 0.05 \\
\hline Mineral premix ${ }^{\dagger}$ & 0.20 & 0.20 \\
\hline Total & 100 & 100 \\
\hline \multicolumn{3}{|c|}{ Calculated chemical composition } \\
\hline $\mathrm{CP}, \%$ & 21.0 & 19.0 \\
\hline $\mathrm{ME}(\mathrm{MJ} / \mathrm{kg})$ & 12.6 & 13.0 \\
\hline $\mathrm{Ca}, \%$ & 0.94 & 0.90 \\
\hline Available P, \% & 0.43 & 0.40 \\
\hline Lys, \% & 1.10 & 0.97 \\
\hline TSAA, $\%$ & 0.87 & 0.66 \\
\hline Thr, \% & 0.77 & 0.70 \\
\hline Trp, \% & 0.26 & 0.23 \\
\hline Val, \% & 0.86 & 0.78 \\
\hline lle, \% & 0.87 & 0.78 \\
\hline Leu, \% & 1.60 & 1.52 \\
\hline Phe, \% & 1.08 & 0.98 \\
\hline Arg, \% & 1.39 & 1.24 \\
\hline His, \% & 0.56 & 0.51 \\
\hline Gly, \% & 0.82 & 0.74 \\
\hline Gly + Ser, \% & 1.78 & 1.62 \\
\hline
\end{tabular}

*Vitamin premix provides the following per kg of diet: VA, $8000 \mathrm{U}$; VD, $3000 \mathrm{U}$; VE, 20 IU; VK, $2 \mathrm{mg}$; VB1, $4 \mathrm{mg}$; riboflavin, $8 \mathrm{mg}$; D-pantothenic acid, $11 \mathrm{mg}$; VB5, 40 mg; VB6, 4 mg; VB12, $0.02 \mathrm{mg}$; biotin, $0.15 \mathrm{mg}$; folic acid, $1.0 \mathrm{mg}$; choline, $700 \mathrm{mg} .{ }^{\dagger}$ Mineral premix provides the following per $\mathrm{kg}$ of diet: Fe (as ferrous sulfate), $80 \mathrm{mg}$; Zn (as zinc sulfate), $75 \mathrm{mg}$; Mn (as manganese sulfate), 80 mg; Cu (as copper sulfate) 10 mg, I (as potassium iodide), 0.40 mg; and Se (as sodium selenite), $0.30 \mathrm{mg}$.

was drawn from a wing vein with a syringe from each chicken. The blood sample was, respectively, collected with the ice-cold normal and heparinized tube. The plasma or serum was obtained by centrifugation at $400 \mathrm{~g}$ at $4^{\circ} \mathrm{C}$ for $10 \mathrm{~min}$ and stored at $-20^{\circ} \mathrm{C}$ for further analysis. Immediately after the blood sample was obtained, broilers were sacrificed by exsanguination after cervical dislocation (Close et al., 1997; Huang et al., 2015). Liver and abdominal fat pad (fat in abdominal area) were weighed and sampled. All tissue samples were snap-frozen in liquid nitrogen and stored at $-80^{\circ} \mathrm{C}$ prior to further analysis.

\section{LPS Treatment}

At 35 days of age, four broilers from each pen and 16 chickens in total in each treatment were selected. In each treatment, half of the chickens were received an intraperitoneal injection of LPS (1 $\mathrm{mg} / \mathrm{kg}$ of body weight, derived from Escherichia coli 055:B5, L2880; Sigma-Aldrich, United States) according to Liu et al. (2016) the other half received a sham injection with saline. During the 4-h period of LPS exposure, feed was withdrawn and the broilers had free access to water. At $4 \mathrm{~h}$ postinjection, all chickens were sacrificed as forementioned above and the duodenum, jejunum, and ileum were sampled, snapfrozen in liquid nitrogen, and stored at $-80^{\circ} \mathrm{C}$ for the analysis of gene expression. The midpoint of duodenum, jejunum, and ileum were obtained and flushed with $5 \mathrm{~mL}$ of ice-cold PBS supplemented with protease inhibitor cocktail according to Burns et al. (2018). The obtained intestinal content was vortexed for $5 \mathrm{~min}$ and then centrifuged at $4^{\circ} \mathrm{C}$ for $30 \mathrm{~min}$, and then the supernatant was collected and stored at $-80^{\circ} \mathrm{C}$ for the measurement of sIgA.

\section{Measurement of slgA Concentrations}

Immunoassay plates (Costar, Corning) were coated with $100 \mu \mathrm{L}$ of goat anti-chicken IgA (A30-103A; Bethyl) dissolved in phosphate buffer solution (PBS, $\mathrm{pH}$ 9.6) and incubated for $1 \mathrm{~h}$ at $37^{\circ} \mathrm{C}$. Each well was washed and blocked overnight with $100 \mu \mathrm{L}$ of $1 \%$ bovine serum albumin (BSA) in PBS. After washing, $100 \mu \mathrm{L}$ of sample and broiler reference serum (RS10-102-3; Bethyl) were added and the plate was incubated for $1 \mathrm{~h}$ at $37^{\circ} \mathrm{C}$. Thereafter, unbound material was washed away and $100 \mu \mathrm{L}$ of HRP-conjugated goat anti-chicken IgA (A30-103P-35; Bethyl) in $1 \% \mathrm{BSA} / \mathrm{PBS}$ was added. After incubating for $1 \mathrm{~h}$ at $37^{\circ} \mathrm{C}$, the plate was washed and $100 \mu \mathrm{L}$ of TMB (CW0050; CWBIO, China) was added. The plate was then allowed to stand for $15 \mathrm{~min}$ at $37^{\circ} \mathrm{C}$. After addition of $50 \mu \mathrm{L}$ of $2.5 \mathrm{M} \mathrm{H}_{2} \mathrm{SO}_{4}$ to stop the reaction, absorbance at $450 \mathrm{~nm}$ was measured in a Titertek Multiskan Plus MKII plate reader.

\section{Plasma Metabolites}

Plasma concentrations of triglyceride (TG), 5-HT, adiponectin (ADP), and non-esterified fatty acid (NEFA) were measured spectrophotometrically using commercial diagnostic kits (Jiancheng Bioengineering Institute, Nanjing, China). Plasma very-low density lipoprotein (VLDL) levels were measured as described by Griffin and Whitehead (1982).

The measurement of plasma tryptophan was measured as follows. Proteins were removed from plasma using 5sulphosalicylic acid dihydrate (SSA, S3147; Sigma) before analyzing amino acid composition. The minimum purity was $99 \%$, but the conditions used to remove the protein varied depending on the protein concentration of the sample. Briefly, $50 \mathrm{mg}$ of pre-cooled SSA was added to each $1 \mathrm{~mL}$ of sample and mixed immediately. Then, the mixture was incubated at $4^{\circ} \mathrm{C}$ for $1 \mathrm{~h}$ and centrifuged at $15,000 \mathrm{~g}$ for $20 \mathrm{~min}$ (at $4^{\circ} \mathrm{C}$ ). The supernatant was obtained and passed through a $0.2 \mu \mathrm{m}$ filter. Finally, the supernatant was examined using an amino acid analyzer (L-8900; Hitachi, Japan).

\section{RNA Analysis}

The expression of genes in the liver, abdominal fat and duodenum tissues was quantified using quantitative real-time polymerase chain reaction (qRT-PCR) with SYBR Green I labeling (04913914001, Roche, United States). The mRNA levels of the cytokines were only measured in duodenum according 
to the result of sIgA in intestinal content. Approximate $0.1 \mathrm{~g}$ tissue sample was homogenized with 10 times Trizol Reagent (15596-026, Invitrogen, San Diego, CA, United States). Total RNA was isolated by the guanidinium isothiocyanate method. The quality of RNA after DNase treatment was tested by electrophoresis on an agarose gel, and the quantity of RNA was determined using a biophotometer (Eppendorf, Germany). Then, $1 \mu \mathrm{g}$ of total RNA was used for reverse transcription with a PrimeScript RT reagent kit (04897030001, Roche, United States) to prepare the cDNA. The primer sequences are shown in Table 2. Real-time PCR analysis was conducted using an Applied Biosystems 7500 Real-time PCR System (Applied Biosystems, Foster, CA, United States). Each RT-reaction served as the template in a $20 \mu \mathrm{L}$ PCR reaction volume containing $0.2 \mu \mathrm{mol} / \mathrm{L}$ of each primer and SYBR Green I labeling (04913914001, Roche, United States). SYBR green fluorescence was detected at the end of each cycle to monitor the amount of PCR product. Real-time PCR was performed at $95^{\circ} \mathrm{C}$ for $10 \mathrm{~s}$, followed by 40 cycles at $95^{\circ} \mathrm{C}$ for $5 \mathrm{~s}$ and $60^{\circ} \mathrm{C}$ for $40 \mathrm{~s}$. SYBR green fluorescence was detected at the end of each cycle to monitor the amount of PCR product. A standard curve was plotted to calculate the efficiency of the real-time PCR primers. The gene-specific primers used for the analysis of chicken gene expression were listed in Table 2.

The relative amount of mRNA of a gene was calculated according to the method of Livak and Schmittgen (2001). The mRNA levels of these genes were normalized to $\beta$-actin levels $(\Delta \mathrm{CT})$. The $\Delta \mathrm{CT}$ was calibrated against an average of the control chickens. The linear amount of target molecules relative to the calibrator was calculated by $2^{-\Delta \Delta C T}$. Therefore, all gene transcription results are reported as the $n$-fold difference relative to the calibrator. The specificity of the amplification product was verified by the standard curve and dissolution curve.

\section{Western Blot Analysis}

Duodenum and abdominal fat tissue samples were homogenized in $1 \mathrm{~mL}$ of lysis buffer (Beyotime, Jiangsu, $\mathrm{CN}$ ) and centrifuged at $12,000 \mathrm{~g}$ for $10 \mathrm{~min}$ at $4^{\circ} \mathrm{C}$. The supernatant was collected.

TABLE 2 | Gene-specific primers used for the analysis of chicken gene expression.

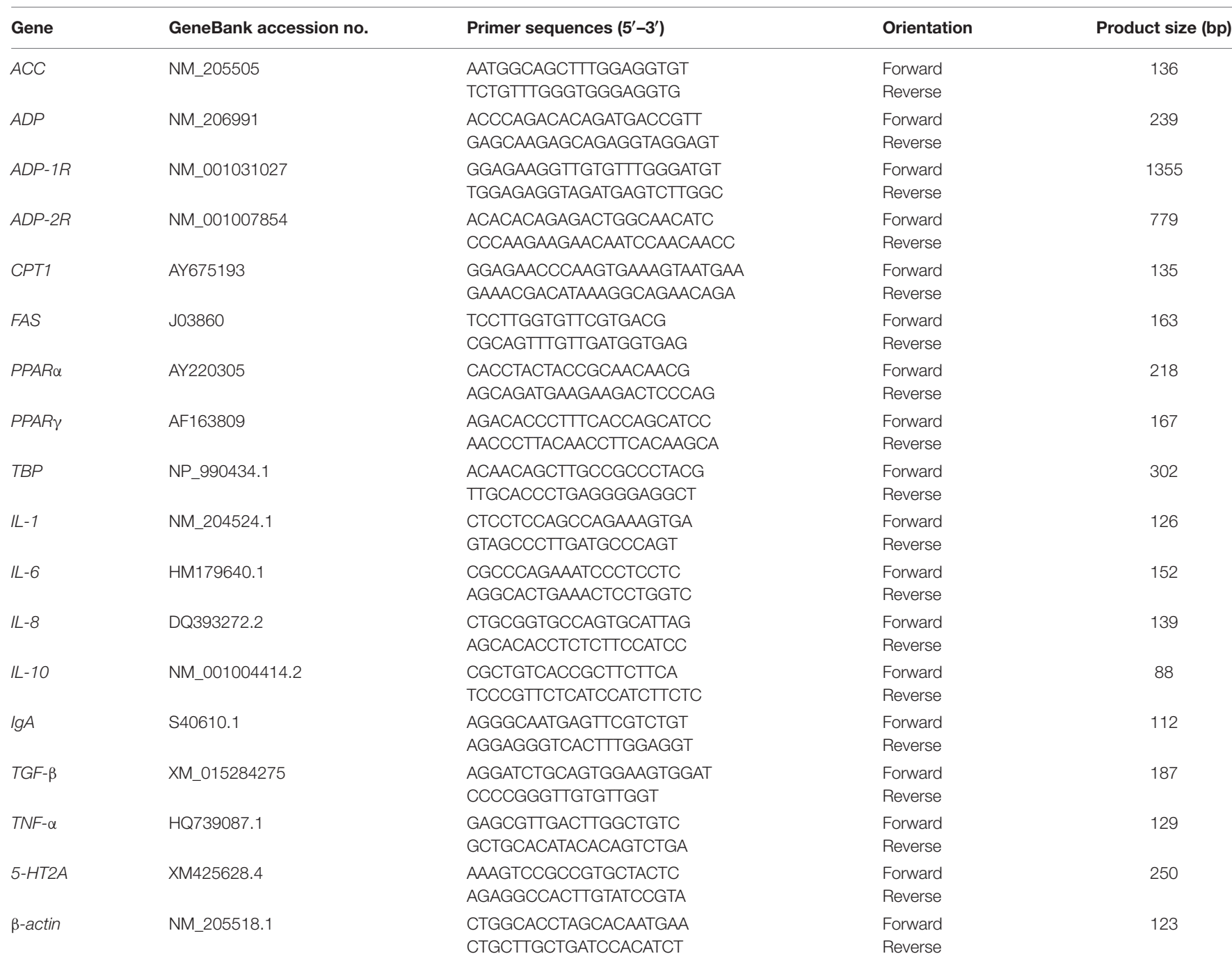


Next, total proteins were extracted and the concentration was measured with a BCA Protein Assay Kit (Beyotime, Jiangsu, China). For western blot analysis, equal amounts of protein (duodenum tissue: $50 \mu \mathrm{g}$; abdominal fat tissue: $30 \mu \mathrm{g}$ ) were denatured for $10 \mathrm{~min}$ at $100^{\circ} \mathrm{C}$ and then separated in 7.5 and $12 \%$ sodium dodecyl sulfate (SDS)-polyacrylamide gels. Proteins were transferred to polyvinylidene fluoride (PVDF) microporous membranes (Millipore) at $200 \mathrm{~mA}$ at $4^{\circ} \mathrm{C}$ for $2 \mathrm{~h}$. After $1 \mathrm{~h}$ in blocking solution (Beyotime) at room temperature, the membranes were incubated overnight at $4^{\circ} \mathrm{C}$ with primary antibodies specific for ADP (aa32-244; LsBio \#LS-C292655) and ADP1R (mAbcam50675; Abcam \#ab50675), rabbit monoclonal antibodies (mAbs) specific for phosphoNF- $\mathrm{B}(\mathrm{NF}-\kappa \mathrm{B})$ p65 (Ser536) (93H1), phosphor-p38 MAPK (Thr180/Tyr182), phospho-p70S6 Kinase (p70S6K) (Thr389) (108D2), phospho-mTOR (Ser2448), total NF-кB p65 (C22B4), p38 MAPK, p70S6K (49D7), and mTOR (all from Cell Signaling Technology, Inc.), and mouse mAbs specific for tubulin (AT819; Beyotime) and $\beta$-actin (AA128; Beyotime). The blots were then incubated for $4 \mathrm{~h}$ at $4^{\circ} \mathrm{C}$ with anti-rabbit or anti-mouse IgGconjugated horseradish peroxidase antibodies (Beyotime), and binding was detected by ECL (Beyotime). Bands were visualized and analyzed using a FUSION device.

\section{Statistical Analysis}

Prior to analysis, all data were examined for the homogeneity and normal distribution plots of variances among the treatments by using UNIVARIATE procedure. For variables feed intake, BW gain, and FCR, a one-way ANOVA model was used to estimate the main effects of 5-HTP treatment on a per-pen basis (SAS version 8e, SAS Institute, 1998). For the variables gene expression and plasma metabolite, a one-way ANOVA model was used to estimate the main effect of feeding treatment for individual broiler. For the data of LPS exposure, a twoway ANOVA model was used to estimate the main effects of 5-HTP and LPS treatment, as well as their interactions for individual chickens. When the main effect of the interaction was significant, multiple comparisons were conducted by Duncan's multiple range analysis. $P<0.05$ was considered statistically significant.

\section{RESULTS}

\section{Growth Performance, Organ Index, and Plasma Metabolites}

The average daily feed intake was not significant influenced $(P>0.05)$ by 5 -HTP treatment in the periods of $8-21$ days and 22-35 days of age. In contrast, the feed intake during the entire experiment period was decreased by 5 -HTP treatment $(P<0.05)$. 5 -HTP treatment led to reduced BW gain in the period of $8-$ 21 days of age $(P=0.050)$ and a trend toward reduced $\mathrm{BW}$ gain $(P=0.056)$ from 8 to 35 days of age, but had no significant influence in the period of 22-35 days of age $(P>0.05$, Table 3$)$. FCR was not changed by 5 -HTP treatment $(P>0.05)$.

In addition, there was a reduction in abdominal fat weight (Figure 1; $P<0.05$ ) but no significant change in liver
TABLE 3 | Effect of dietary 5-hydroxytryptophan (0.2\%, 5-HTP) on growth performance of broilers.

\begin{tabular}{lcrc}
\hline & Control & 5-HTP & Significance \\
\hline Initial body weight at 7-day age, g & $141.2 \pm 5.37$ & $139.0 \pm 6.61$ & NS \\
Feed intake, g/d & & & \\
8-21 days & $55.8 \pm 0.92$ & $52.5 \pm 1.64$ & NS \\
22-35 days & $128.5 \pm 1.66$ & $124.5 \pm 2.87$ & NS \\
8-35 days & $92.2 \pm 0.73^{\mathrm{a}}$ & $88.5 \pm 1.25^{\mathrm{b}}$ & 0.033 \\
Body weight gain, g/d & & & \\
8-21 days & $39.9 \pm 1.23$ & $36.3 \pm 0.64$ & 0.050 \\
22-35 days & $75.9 \pm 1.55$ & $73.7 \pm 1.58$ & NS \\
8-35 days & $57.9 \pm 0.80$ & $55.0 \pm 1.02$ & 0.057 \\
FCR, g/g & & & \\
8-21 days & $1.40 \pm 0.02$ & $1.44 \pm 0.02$ & NS \\
22-35 days & $1.70 \pm 0.04$ & $1.69 \pm 0.05$ & NS \\
8-35 days & $1.59 \pm 0.02$ & $1.61 \pm 0.03$ & NS \\
\hline
\end{tabular}

Values were presented as Mean \pm SEM $(n=4) ;{ }^{a, b} P<0.05 ; N S$, not significant.

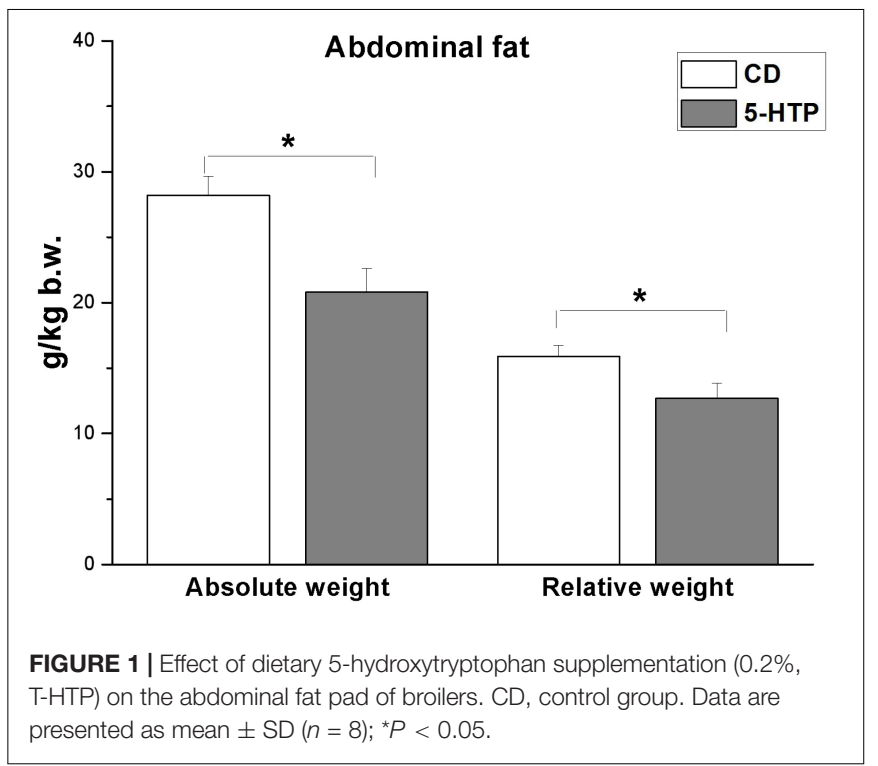

weight $(P>0.05$, data not shown). There was no significant difference $(P>0.05)$ in plasma TG, 5-HT, VLDL, ADP, NEFA, and tryptophan levels between 5-HTP broilers and control ones (Table 4).

\section{Expression of Genes Associated With Lipid Metabolism in Liver and Abdominal Fat Pad}

5-HTP treatment had no significant effect $(P>0.05)$ on the mRNA level of 5-hydroxytryptamine receptor 2A (5-HT2A) in the liver and abdominal fat pad (Figure 2A). The mRNA level of fatty acid synthase (FAS), acetyl-CoA carboxylase (ACC), carnitine palmitoyltransferase 1 (CPT1), and peroxisome proliferator-activated receptor $\alpha$ (PPAR $\alpha)$ in the liver was unchanged by 5-HTP treatment $(P>0.05$, Figure 2B). In abdominal fat, the mRNA levels of $\operatorname{PPAR} \gamma$, lipoprotein lipase 
TABLE 4 | Effect of dietary 5-hydroxytryptophan treatment (0.2\%, 5-HTP) on plasma concentrations of tryptophan, triglyceride (TG), very-low density lipoprotein (VLDL), non-esterified fatty acid (NEFA), adiponectin (ADP), and 5-hydroxytryptamine (5-HT).

\begin{tabular}{lccc}
\hline & Control & 5-HTP & Significance \\
\hline TG, mmol/L & $0.27 \pm 0.04$ & $0.26 \pm 0.03$ & NS \\
VLDL, Abs 1000 & $12.4 \pm 2.20$ & $13.8 \pm 1.75$ & $\mathrm{NS}$ \\
$\mathrm{NEFA}, \mathrm{mmol} / \mathrm{L}$ & $1.82 \pm 0.12$ & $1.84 \pm 0.08$ & $\mathrm{NS}$ \\
$\mathrm{ADP}, \mathrm{ng} / \mathrm{mL}$ & $3.07 \pm 0.07$ & $3.24 \pm 0.30$ & $\mathrm{NS}$ \\
$5-\mathrm{HT}, \mathrm{ng} / \mathrm{mL}$ & $43.8 \pm 3.30$ & $45.6 \pm 2.53$ & $\mathrm{NS}$ \\
Tryptophan, g/L & $9.13 \pm 0.37$ & $9.44 \pm 0.34$ & $\mathrm{NS}$ \\
\hline
\end{tabular}

Data were presented as Mean $\pm S D(n=8) ; N S: P>0.05$.

(LPL), CPT1, and ADP were not significantly influenced by 5 HTP treatment $(P>0.05$, Figures $2 B, C)$. By contrast, the mRNA level of adiponectin receptor 1 (ADP1R) $(P=0.057)$ and ADP2R $(P=0.069)$ tended to be increased in 5-HTP-treated chickens compared with control (Figure 2C). The protein expression levels of ADP and ADP1R, however, were not changed by 5-HTP treatment $(P>0.05$; Figure 2D).

\section{Concentration of sIgA in Serum and Intestinal Contents}

The IgA concentration in serum from the 5-HTP group fell after LPS treatment $(P<0.05$; Figure 3A), whereas LPS had no detectable effect $(P>0.05)$ in CD chickens. Duodenal contents from 5-HTP chickens showed significantly higher sIgA concentrations than those from CD chickens $(P<0.05)$; however, LPS treatment reduced the sIgA concentration in the duodenum of 5-HTP chickens but not in that of CD chickens $(P<0.05$; Figure 3B). By contrast, the IgA concentration in jejunal contents was unaffected by LPS or diet $(P>0.05$; Figure $3 \mathrm{C})$. CD-LPS chickens showed lower sIgA levels in the ileum contents than 5-HTP chickens $(P<0.05$; Figure 3D).

\section{Expression of Cytokine-Encoding mRNA in Duodenum}

Treatment with 5-HTP decreased expression of mRNA encoding interleukin 1 ( $I L-1, P<0.05), I L-6(P<0.01), I L-10(P<0.001)$, tumor necrosis factor $\alpha(T N F-\alpha)(P<0.01)$, and transforming growth factor $\beta$ (TGF- $\beta, P<0.001$ ) (Figures 4A-E). Treatment with 5-HTP and LPS had a significant effect $(P<0.05)$ on $\operatorname{IgA}$ mRNA levels: IgA mRNA levels in the 5-HTP group $(P<0.05)$, but not in the CD group $(P<0.05)$, were increased by LPS (Figure 4F). LPS treatment led to significant upregulation of $I L-1(P<0.05)$, IL-10 $(P<0.05)$, and TGF- $\beta(P<0.01)$ mRNA. However, LPS tended to downregulate TNF- $\alpha$ mRNA levels $(P=0.098)$. IL-6 mRNA levels were not affected by LPS $(P>0.05)$.

\section{Phosphorylation of mTOR, MAPK, and NF- $\mathrm{B}$ in Duodenum}

Compared with the CD group, treatment with 5-HTP increased phosphorylation of ribosomal p70S6K $(P<0.05$, Figure 5A), but suppressed phosphorylation of nuclear factor-kappa B (NFкВ) $(P<0.05$; Figure 5C) and mitogen-activated protein kinase (p38 MAPK) $(P<0.05$; Figure 5D). By contrast, there were no differences between the control birds and birds treated with LPS. Neither LPS nor 5-HTP had a significant effect on phosphorylation of $\operatorname{mTOR}(P>0.05$; Figure 5B).

\section{DISCUSSION}

\section{5-HTP Suppresses Feed Intake}

In the present study, 5-HTP was supplemented in the broiler diet for 28 days and the zootechnical performance was measured at 35 days of age, which is in the period of maximum growth rate of body weight body of modern strain of broilers (Scheuermann et al., 2003). The results presented herein show that administration of 5-HTP reduced both FI and BW gain in broilers. The lack of change in the FCR indicated that the reduction in BW gain was caused mainly by the reduced FI. It is interesting to note that the variation of feed intake and body weight gain was greater in 5-HTP treatment, compared with that of control. As the variation of FCR in 5-HTP group was comparable to control group, the variation in body weight gain seems to be a result of feed intake. 5-HT has an inhibitory effect on appetite in mammals (Brewerton, 1995) and avian species (Steffens et al., 1997). In human, increased activity of the 5HT system suppresses feeding behavior (Brewerton, 1995). 5-HT activates pro-opiomelanocortin neurons via the 5 -HT2C receptor while inhibiting neuropeptide $\mathrm{Y} /$ agouti-related protein neurons via the 5-HT1B receptor (Heisler et al., 2002). In chicken, ICV injection of serotonin decreased food intake (Zendehdel et al., 2017). Central 5-HT is associated with feeding/foraging behavior of chicken (de Haas and van der Eijk, 2018). Hence, the present result suggests that 5-HTP administration suppresses appetite and reduces feed intake of broilers via the serotonergic system.

\section{5-HTP Reduces Abdominal Fat Accumulation}

Accumulating evidence suggests that peripheral 5-HT may affect the energy homeostasis (Tecott, 2007). The present results show that dietary treatment with 5-HTP inhibits accumulation of abdominal fat without affecting the level of tryptophan in plasma, indicating that the change is induced mainly by 5 -HTP. In mammal, peripherally, 5-HT plays a role in development of obesity (Haub et al., 2011; Kim et al., 2011). Pharmacological inhibition of 5-HT synthesis or TPH1 knockout in adipose tissues leads to inhibition of lipogenesis in epididymal white adipose tissue, suggesting 5-HT has localized effects on adipose tissues (Oh et al., 2015). The present result indicates that 5-HT plays a different effect from that of mammal on lipid metabolism in chicken. De novo lipogenesis in birds, as well as in humans, occurs mainly (although not exclusively) in the liver (Bedu et al., 2002). Therefore, we investigated expression of genes related to lipogenesis in both liver and abdominal fat. In the liver, expression of mRNA encoding FAS and ACC was unaltered by 5-HTP treatment, indicating that hepatic lipogenesis was not affected. In abdominal fat, LPL and PPAR $\gamma$ play roles in lipid 

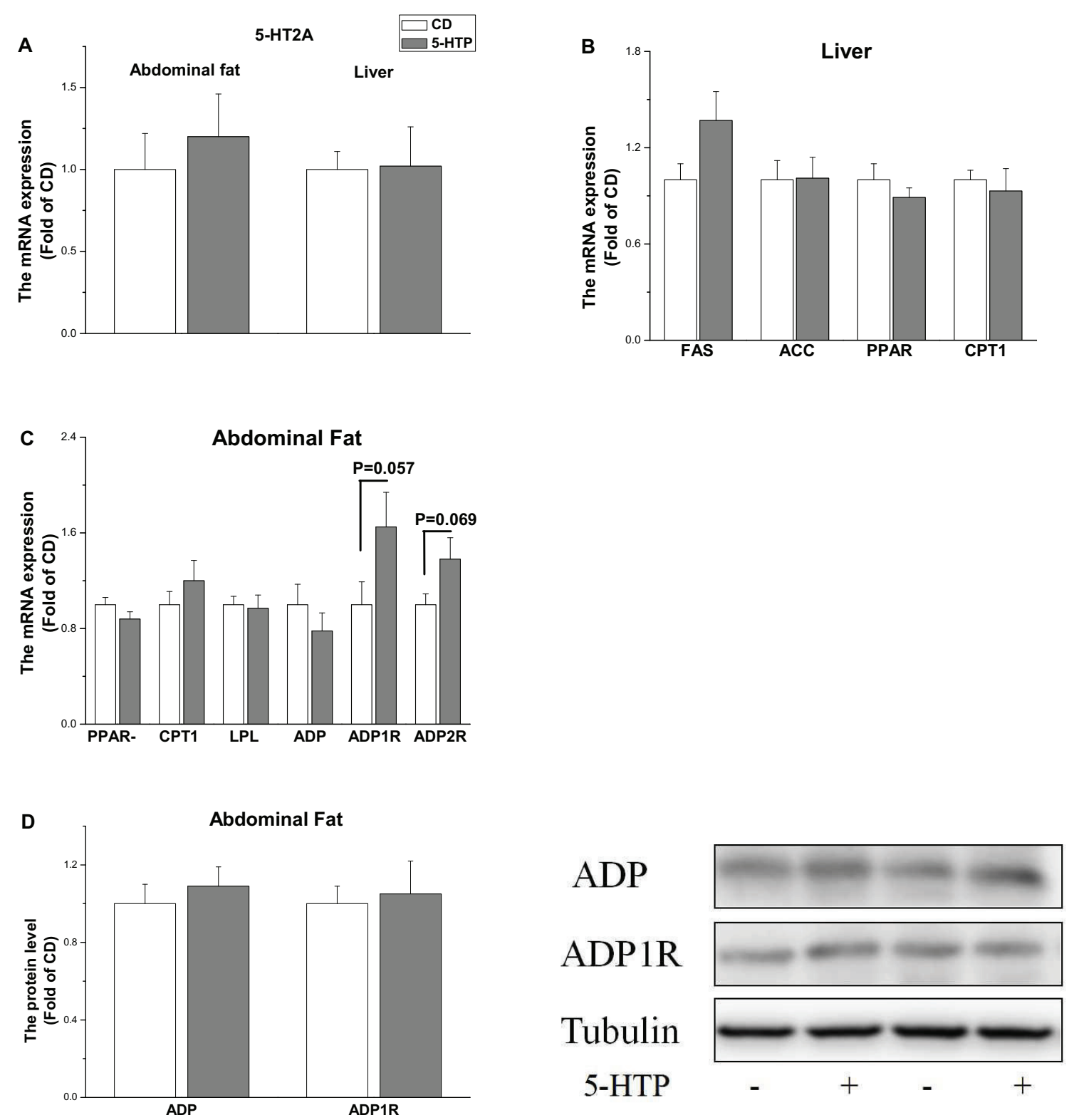

FIGURE 2 | Effect of dietary 5-hydroxytryptophan supplementation (0.2\%, 5-HTP) on the expression level of genes related to lipid metabolism in the liver and abdominal fat pad (A) serotonin receptor 2A (5-HT2A) in the liver and abdominal fat; (B) fatty acid synthase (FAS), acetyl-CoA carboxylase (ACC), carnitine palmitoyltransferase 1 (CPT1), and peroxisome proliferator-activated receptor (PPAR) $\alpha$ in the liver; and (C) PPAR $\gamma, \mathrm{CPT} 1$, lipoprotein lipase (LPL), adiponectin (ADP), and ADP1R and ADP2R in abdominal fat; (D) ADP and ADP1R proteins in abdominal fat. Data are presented as the mean $\pm \operatorname{SD}(n=6)$.

deposition and adipocyte differentiation (Schoonjans et al., 1996; Wang and Eckel, 2009). The unchanged expression of PPAR $\gamma$ and LPL mRNA in 5-HTP chickens indicates that adipocyte development is not affected by 5 -HTP treatment. The mRNA expression of gene encoding 5-HT2A in both liver and abdominal fat was consistent with the finding of unaffected circulating levels of 5-HT. In rats, however, the endogenous serotonin levels increased in the plasma and brain at $4 \mathrm{~h}$ after 5-HTP administrations (Sharma et al., 2019).

We further investigated expression of two genes related to lipid oxidation: CPT1 and PPAR $\alpha$ (Preidis et al., 2017).
Transcription of PPAR $\alpha$ and CPT1 in liver was unchanged by 5 -HTP, suggesting that 5-HTP plays little if any role in lipid utilization by the liver. Adipose tissue affects energy homeostasis by ADP, which promotes fatty acid oxidation and glucose utilization (Combs et al., 2001; Zhou et al., 2005; Liu et al., 2012). ADPR agonists and ADP sensitizers may serve as versatile treatment strategies for obesity-linked diseases such as metabolic syndrome and diabetes (Kadowaki and Yamauchi, 2005). The chickens with a high pecking tendency have low peripheral 5-HT (de Haas and van der Eijk, 2018). Moreover, the locomotor activity is higher in the line selected for high 

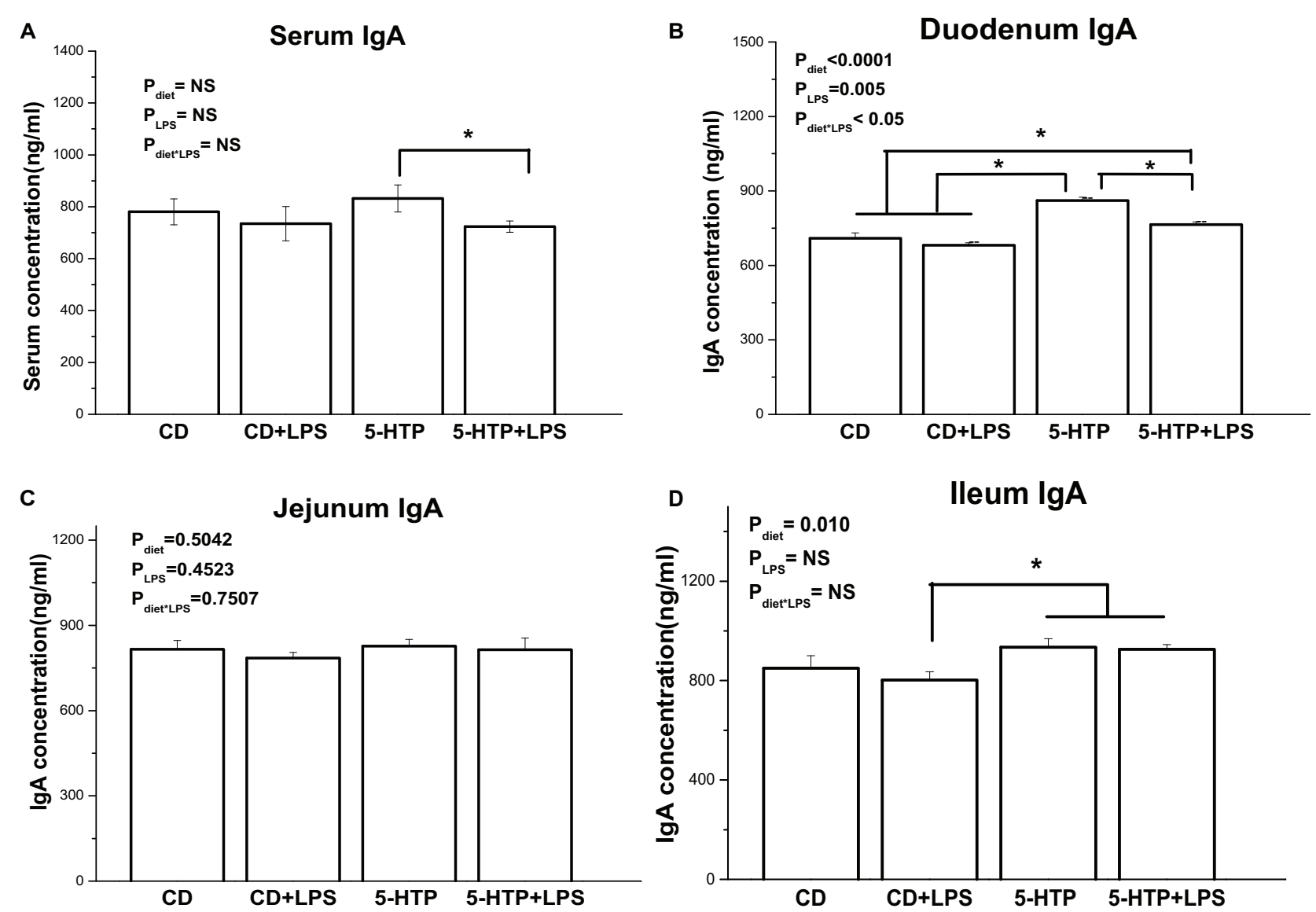

FIGURE 3 | Effect of dietary 5-hydroxytryptophan supplementation (0.2\%, 5-HTP) and lipopolysaccharide (LPS, 1 mg/kg of body weight) on secretory immunoglobulin A (slgA) concentrations in serum and intestinal contents. (A) serum slgA; (B) slgA in duodenum contents; (C) slgA in jejunum contents; and (D) slgA in ileum contents. Data are presented as the mean $\pm \mathrm{SD}(n=8) ;{ }^{*} P<0.05$.

levels of feather pecking compared to control and the line selected for low levels of feather pecking (Kjaer, 2009). The acutely enhanced 5-HT level decreases motor activities of chicks (Matsunami et al., 2012). Hence, the involvement of locomotion activity on the energy expenditure remains to be elucidated. Here, we found that neither circulating ADP levels nor ADP1R and ADP2R mRNA and ADP1R protein levels in abdominal fat were altered by 5-HTP treatment, suggesting that ADP may not be a target of 5-HTP. Collectively, the present result suggests that the reduced feed intake should be responsible for the suppressed abdominal fat accumulation by 5-HTP treatment. Moreover, the effect of 5-HTP on lipid utilization should be investigated further.

The reduced abdominal fat deposit is accompanied with the increased muscle fat accumulation and improved polyunsaturated fatty acid (PUFA) contents (Saleh et al., 2012, 2014). Moreover, the 5-HT receptor signaling could be influenced by the lipid microdomains (lipid raft) in plasma membrane via the regulatory effect on G-proteins and meanwhile, the lipid raft molecular organization and raft-associated protein distribution are highly susceptible to modulation by long chain $n-3$ PUFAs (Liu S. Q. et al., 2018). Hence, the effect of 5-HTP on the fat accumulation and the fatty acid profile in muscle needs to be investigated further.

\section{5-HTP Is Beneficial to the Intestinal Immune Function With the Involvement of $\mathrm{mTOR} / \mathrm{p} 70$ S6K Signaling Pathway}

5 -HT is produced by enterochromaffin cells and can regulate gut physiology by promoting intestinal inflammation (Margolis et al., 2014). The 5-HT type 7 receptor, one of the most recently identified members of the 5-HT receptor family, plays a critical role in regulating mucosal inflammation and immune responses (Kim et al., 2013). Therefore, we examined the effect of relative long-term 5-HTP supplementation (4 weeks) on LPS-induced gut inflammation in chickens.

sIgA, the most abundant immunoglobulin in mucosal secretions, plays an important role in the intestinal mucosal immune system and in maintenance of mucosal homeostasis. In chickens, IgA secreted by the intestine is similar to mammalian sIgA and is associated with a protein homologous to a mammalian secretory component of 350,000 Daltons (Watanabe et al., 1975). The increased sIgA concentration in 

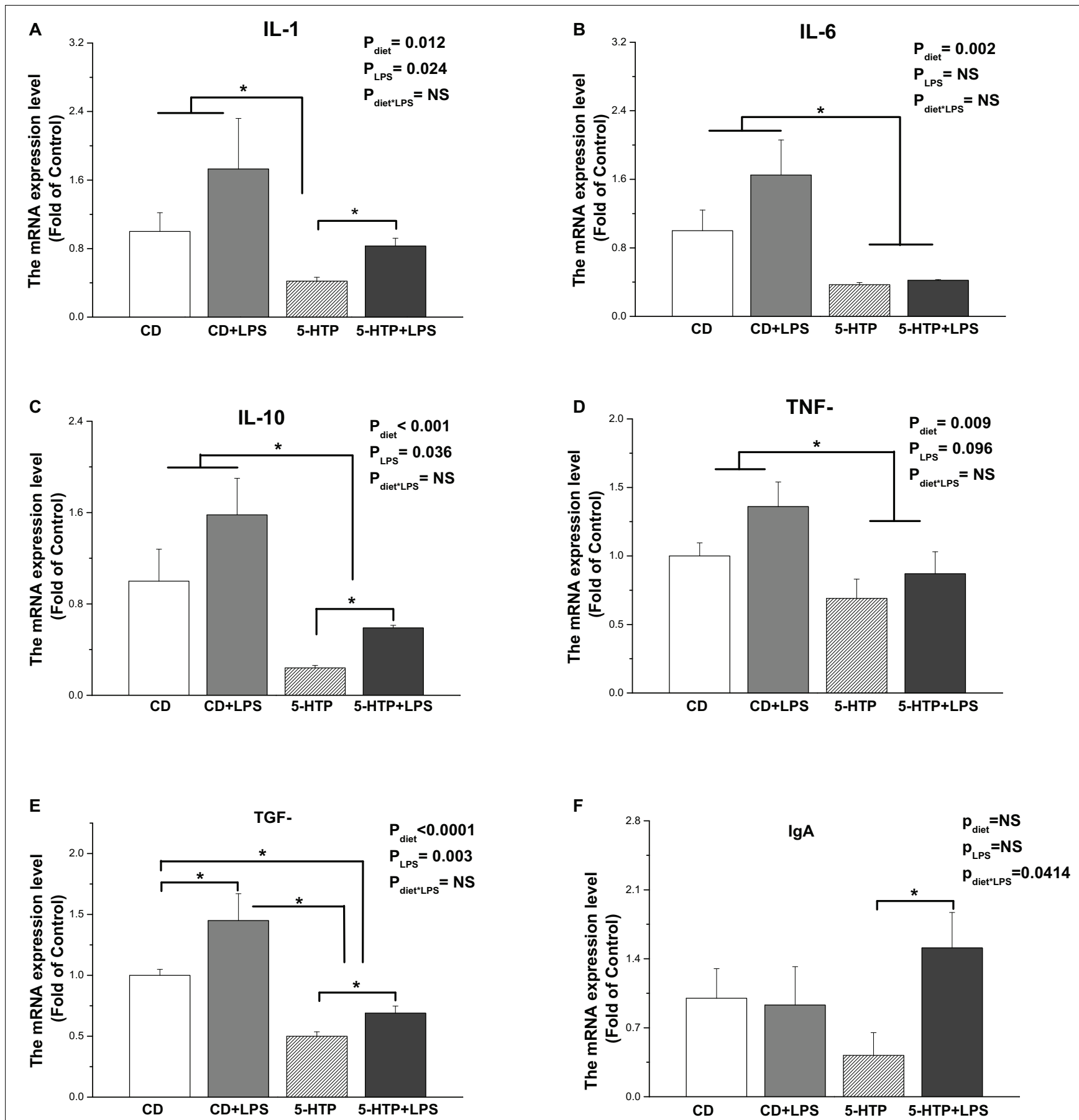

FIGURE 4 | Effect of dietary 5-hydroxytryptophan supplementation (0.2\%, 5-HTP) and lipopolysaccharide (LPS, 1 mg/kg of body weight) on cytokine mRNA levels in the duodenum. (A) Interleukin (IL)-1; (B) IL-6; (C) IL-10; (D) transforming growth factor- $\beta$ (TGF- $\beta$ ); (E) tumor necrosis factor- $\alpha$ (TNF- $\alpha$ ); and (F) IgA. CD, control group; data are presented as the mean $\pm \mathrm{SD}(n=8) ;{ }^{\star} P<0.05$.

the duodenum and ileum of 5-HTP chickens indicates that 5HTP treatment may increase secretion of sIgA into the intestinal tract. Furthermore, 5-HTP treatment decreased the mRNA levels of IL-1, IL-6, IL-10, TNF- $\alpha$, and TGF- $\beta$ in the duodenum. This result is in contrast to the observations in mammals. Ghia et al. (2009) found that 5-HT stimulated production of IL-1 and IL-6 by peritoneal resident macrophages. Direct exposure of colon epithelial cells to 5-HT triggers inflammatory reactions (Regmi et al., 2014). After LPS administration, however, we found that 5-HTP supplementation increased serum and duodenal sIgA concentrations, in contrast to the lack of response noted in CD chickens. This result was in accordance with the significant 

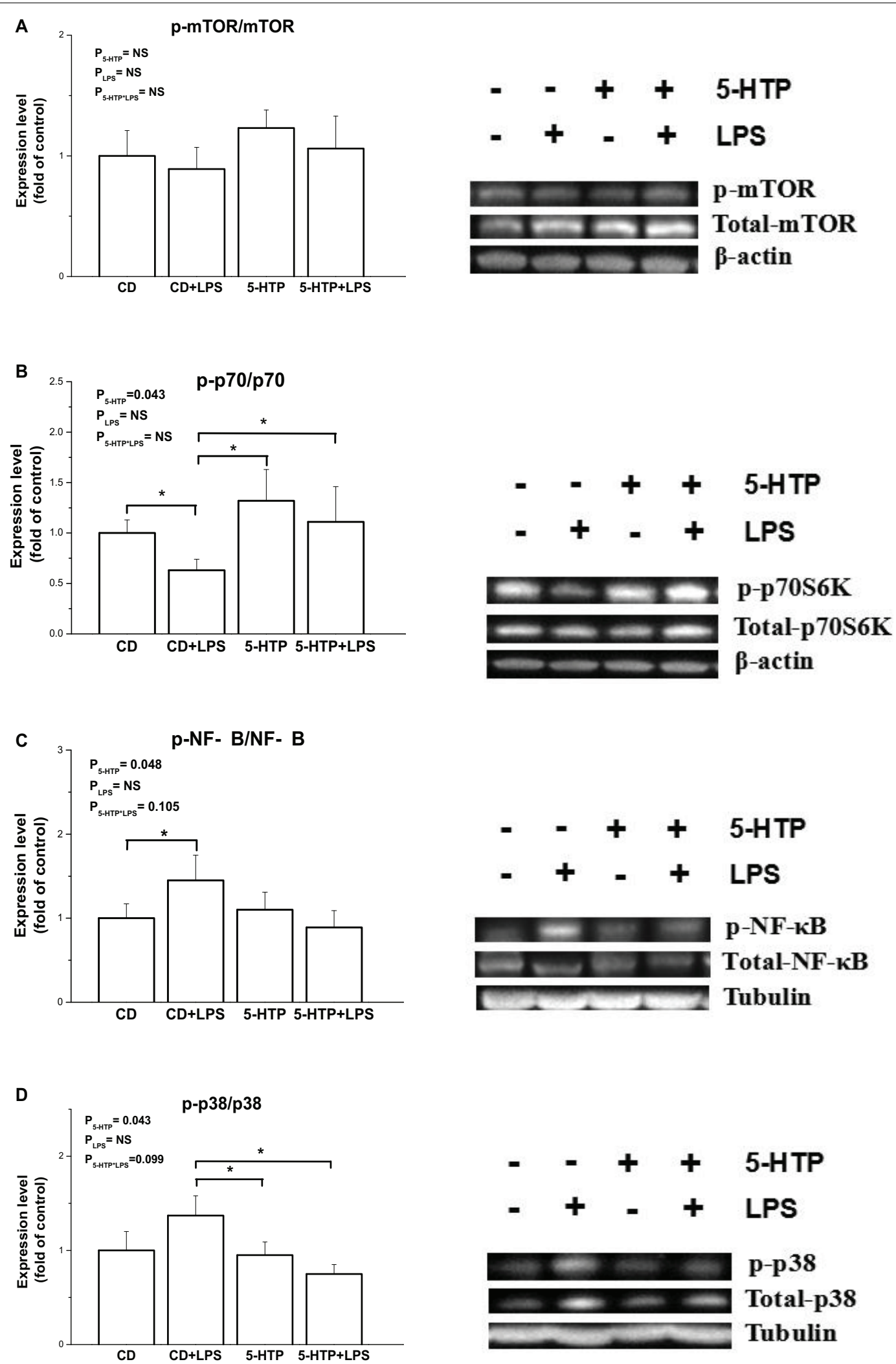

FIGURE 5 | Effect of dietary 5-hydroxytryptophan supplementation (0.2\%, 5-HTP) and lipopolysaccharide (LPS) (intraperitoneal injection at a dose of 1 mg/kg of body weight) on phosphorylation of signal molecules. (A) Ribosomal p70S6 kinase (p70S6K), (B) mammalian target of rapamycin (mTOR), (C) nuclear factor-kappa $\mathrm{B}(\mathrm{NF}-\kappa \mathrm{B})$ p65, and (D) p38 mitogen-activated protein kinase (MAPK), in the duodenum. CD, control group; data are presented as the mean \pm SD $(n=8)$; ${ }^{*}<0.05$. 
interaction between 5-HTP and LPS treatments on duodenum IgA mRNA level, suggesting that 5-HTP improves IgA secretion upon to LPS challenge. As the interaction of 5-HTP and LPS was only observed in duodenum in the present study, we further determined the transcriptional level of relevant cytokines. LPS treatment significantly changed the expression level of IL-1, IL-10, and TGF- $\beta$, suggesting that LPS induces inflammation response. The lack of interaction of LPS and 5-HTP on all the expression of measured genes, however, indicated that 5HTP had no regulation on LPS-induced inflammation at the present condition. Hence, the effect of 5-HTP on LPS-induced inflammation response needs to be investigated further.

mTOR, a highly conserved and ubiquitously expressed signaling molecule, plays roles in cell growth and proliferation and other cellular functions. mTOR senses metabolic signals and exerts anabolic effects by stimulating protein synthesis and ribosomal biogenesis, thereby increasing cell proliferation and promoting cell survival (Wang et al., 2011; Fielhaber et al., 2012). mTOR exerts its regulatory effects by stimulating phosphorylation of the downstream target protein p70S6K. 5-HT activates the mTOR pathway in mammals; for example, exposure to 5-HT activates the hepatic mTOR/p70S6K pathway in rat liver (Li et al., 2016). Our previous study indicated that the mTOR pathway is associated with intestinal immunity (Liu et al., 2016; Liu J. J. et al., 2018). Our present data show that the 5-HTP diet restored the phosphorylation level of p70S6K, which was inhibited by LPS, indicating that the p70S6K signaling pathway may play a role in the regulatory effects of 5-HTP on intestinal mucosal immunity in chickens.

In LPS-stimulated murine macrophages, cross-talk between the mTOR and NF- $\mathrm{B}$ pathways plays a role in LPS-induced responses (Dos Santos et al., 2007). The Akt/mTOR cascade differentially modulates LPS-induced cytokine production by peripheral blood mononuclear cells (Schaeffer et al., 2011). Blocking the mTOR pathway in human monocytes suppresses expression of chemokines by modulating the MAPK and NF- $\kappa$ B p65-mediated signaling pathways (Lin et al., 2014). Here, we found that phosphorylation of NF- $\kappa B$ and p38 MAPK in 5-HTP-treated chickens was inhibited while p-p70 was stimulated, regardless of LPS administration. Adversely, exposure to 5-HT induces inflammatory reactions in colon epithelial cells and the underlying mechanism is associated with Nox2-activated signaling pathways, including ERK/p38 MAPK and NF-кB (Regmi et al., 2014). Hence, the pathway of 5-HTP regulating intestinal immune function remains to be elucidated. In line with the result of cytokine gene expression, no detectable interaction of 5-HTP and LPS was observed. In the present study, LPS had no significant influence on the phosphorylation levels of mTOR, p70, NF- $\mathrm{B}$, and p38 MAPK. However, the increased phosphorylation of NF- $\mathrm{B}$ was detected in control chickens in response to LPS, suggesting

\section{REFERENCES}

Bedu, E., Chainier, F., Sibille, B., Meister, R., Dallevet, G., Garin, D., et al. (2002). Increased lipogenesis in isolated hepatocytes from cold-acclimated ducklings. Am. J. Physiol. Regul. Integr. Comp. Physiol. 283, 1245-1253. that the activated NF- $\kappa \mathrm{B} / \mathrm{p} 38$ pathway by LPS treatment cannot be excluded, as the phosphorylation may occur quickly (Liu et al., 2016; Liu J. J. et al., 2018). Collectively, the results suggest that 5-HTP is beneficial to intestinal immune function with the involvement of $\mathrm{mTOR} / \mathrm{p} 70 \mathrm{~S} 6 \mathrm{~K}$ and MAPK/NF$\kappa \mathrm{B}$ pathway.

\section{CONCLUSION}

Taken together, the results presented herein suggest that dietary supplementation with 5 -HTP reduces feed intake and the accumulation of abdominal fat and is beneficial to the intestinal immune function.

\section{DATA AVAILABILITY STATEMENT}

The sequencing data has been deposited into Figshare (DOI: 10.6084/m9.figshare.2291212).

\section{ETHICS STATEMENT}

The animal study was reviewed and approved by the Animal Care and Use Committee of Shandong Agricultural University, the Guidelines for Experimental Animals established by the Ministry of Science and Technology.

\section{AUTHOR CONTRIBUTIONS}

HW, SL, and HL conceived and designed the experiments and wrote the manuscript. HW and SL performed the experiments and analyzed the data. JL and LW conducted some measurements. XW, JZ, and HJ provided essential reagents. All authors read and approved the final manuscript.

\section{FUNDING}

This work was supported by the National Key R\&D Programmes of China (grant number 2016YFD0500510), Shandong Key Research and Development Program (2018GNC111008), and the National Natural Science Foundation of China (31772619 and 31472114).

\section{ACKNOWLEDGMENTS}

We greatly thank the reviewers for their valuable comments and suggestions on the manuscript.

Birdsall, T. C. (1998). 5-Hydroxytryptophan: a clinically-effective serotonin precursor. Altern. Med. Rev. 3, 271-280.

Brady, L., Romsos, D. R., and Leveille, G. A. (1976). In vivo estimation of fatty acid synthesis in the chicken (Gallus domesticus) utilizing 3H2O. Comp. Biochem. Physiol. B 54, 403-407. doi: 10.1016/0305-0491(76)90265-0 
Brewerton, T. D. (1995). Toward a unified theory of serotonin dysregulation in eating and related disorders. Psychoneuroendocrinology 20, 561-590. doi: 10. 1016/0306-4530(95)00001-5

Burns, P., Oddi, S., Forzani, L., Tabacman, E., Reinheimer, J., and Vinderola, G. (2018). Variability in gut mucosal secretory IgA in mice along a working day. BMC Res. Notes 11:98. doi: 10.1186/s13104-018-3213-0

Chen, C., Wang, H., Jiao, H., Wang, X., Zhao, J., and Lin, H. (2018). Feed habituation alleviates decreased feed intake after feed replacement in broilers. Poult. Sci. 97, 733-742. doi: 10.3382/ps/pex358

Cirillo, C., Vanden Berghe, P., and Tack, J. (2011). Role of serotonin in gastrointestinal physiology and pathology. Minerva Endocrinol. 36, 311-324.

Close, B., Banister, K., Baumans, V., Bernoth, E. M., Bromage, N., Bunyan, J., et al. (1997). Recommendations for euthanasia of experimental animals: Part 2. DGXT of the European Commission. Lab. Anim. 31, 1-32. doi: 10.1258/ 002367797780600297

Combs, T. P., Berg, A. H., Obici, S., Scherer, P. E., and Rossetti, L. (2001). Endogenous glucose production is inhibited by the adipose-derived protein Acrp30. J. Clin. Invest. 108, 1875-1881. doi: 10.1172/jci14120

Crane, J. D., Palanivel, R., Mottillo, E. P., Bujak, A. L., Wang, H., Ford, R. J., et al. (2015). Inhibiting peripheral serotonin synthesis reduces obesity and metabolic dysfunction by promoting brown adipose tissue thermogenesis. Nat Med. 21, 166-172. doi: $10.1038 / \mathrm{nm} .3766$

de Haas, E. N., and van der Eijk, J. A. J. (2018). Where in the serotonergic system does it go wrong? Unravelling the route by which the serotonergic system affects feather pecking in chickens. Neurosci. Biobehav. Rev. 95, 170-188. doi: 10.1016/j.neubiorev.2018.07.007

Donato, T. C., Baptista, A. A., Garcia, K. C., Smaniotto, B. D., Okamoto, A. S., Sequeira, J. L., et al. (2015). Effects of 5-hydroxytryptophan and m-hydroxybenzylhydrazine associated to Lactobacillus spp. on the humoral response of broilers challenged with Salmonella enteritidis. Poult Sci. 94, 20812087. doi: $10.3382 / \mathrm{ps} / \mathrm{pev} 206$

Dong, X. Y., Azzam, M. M., Rao, W., Yu, D. Y., and Zou, X. T. (2012). Evaluating the impact of excess dietary tryptophan on laying performance and immune function of laying hens reared under hot and humid summer conditions. $\mathrm{Br}$. Poult. Sci. 53, 491-496. doi: 10.1080/00071668.2012.719149

Dong, Y., Han, Y., Wang, Z., Qin, Z., Yang, C., Cao, J., et al. (2017). Role of serotonin on the intestinal mucosal immune response to stress-induced diarrhea in weaning mice. BMC Gastroenterol. 17:82. doi: 10.1186/s12876-0170634-5

Dos Santos, S., Delattre, A. I., De Longueville, F., Bult, H., and Raes, M. (2007). Gene expression profiling of LPS-stimulated murine macrophages and role of the NF-kappaB and PI3K/mTOR signaling pathways. Ann. N. Y. Acad. Sci. 1096, 70-77. doi: 10.1196/annals.1397.071

El-Merahbi, R., Löffler, M., Mayer, A., and Sumara, G. (2015). The roles of peripheral serotonin in metabolic homeostasis. FEBS Lett. 589, 1728-1734. doi: 10.1016/j.febslet.2015.05.054

Fielhaber, J. A., Carroll, S. F., Dydensborg, A. B., Shourian, M., Triantafillopoulos, A., Harel, S., et al. (2012). Inhibition of mammalian target of rapamycin augments lipopolysaccharide-induced lung injury and apoptosis. J. Immunol. 188, 4535-4542. doi: 10.4049/jimmunol.1003655

Ghia, J. E., Li, N., Wang, H., Collins, M., Deng, Y., El-Sharkawy, R. T., et al. (2009). Serotonin has a key role in pathogenesis of experimental colitis. Gastroenterology 137, 1649-1660. doi: 10.1053/j.gastro.2009.08.041

Griffin, H. D., and Whitehead, C. C. (1982). Plasma lipoprotein concentrationas an indicator of fatness in broilers: development and use of a simple assay for plasma very low density lipoproteins. Br. Poult. Sci. 23, 307-313. doi: 10.1080/ 00071688208447962

Haub, S., Ritze, Y., Ladel, I., Saum, K., Hubert, A., Spruss, A., et al. (2011). Serotonin receptor type 3 antagonists improve obesity-associated fatty liver disease in mice. J. Pharmacol. Exp. Ther. 339, 790-798. doi: 10.1124/jpet.111.181834

Heisler, L. K., Cowley, M. A., Tecott, L. H., Fan, W., Low, M. J., Smart, J. L., et al. (2002). Activation of central melanocortin pathways by fenfluramine. Science 297, 609-611. doi: 10.1126/science.1072327

Huang, C., Jiao, H., Song, Z., Zhao, J., Wang, X., and Lin, H. (2015). Heat stress impairs mitochondria functions and induces oxidative injury in broiler chickens. J. Anim. Sci. 2015, 2144-2153. doi: 10.2527/jas.2014-8739

Kadowaki, T., and Yamauchi, T. (2005). Adiponectin and adiponectin receptors. Endocr. Rev. 26, 439-451. doi: 10.1210/er.2005-0005
Kim, H. J., Kim, J. H., Noh, S., Hur, H. J., Sung, M. J., Hwang, J. T., et al. (2011). Metabolomic analysis of livers and serum from high-fat diet induced obese mice. J. Proteome Res. 10, 722-731. doi: 10.1021/pr100892r

Kim, J. J., Bridle, B. W., Ghia, J. E., Wang, H., Syed, S. N., Manocha, M. M., et al. (2013). Targeted inhibition of serotonin type 7 (5-HT7) receptor function modulates immune responses and reduces the severity of intestinal inflammation. J. Immunol. 190, 4795-4804. doi: 10.4049/jimmunol.1201887

Kjaer, J. B. (2009). Feather pecking in domestic fowl is genetically related to locomotor activity levels: implications for a hyperactivity disorder model of feather pecking. Behav. Genet. 39, 564-570. doi: 10.1007/s10519-009-9280-1

Li, X., Guo, K., Li, T., Ma, S., An, S., Wang, S., et al. (2016). 5-HT 2 receptor mediates high-fat diet-induced hepatic steatosis and very low density lipoprotein overproduction in rats. Obes Res Clin Pract. 12(Suppl 2), 16-28. doi: 10.1016/j.orcp.2016.03.015

Lin, H. Y., Chang, K. T., Hung, C. C., Kuo, C. H., Hwang, S. J., Chen, H. C., et al. (2014). Effects of the mTOR inhibitor rapamycin on monocyte-secreted chemokines. BMC. Immunol. 15:37. doi: 10.1186/s12865-014-0037-0

Liu, Q., Yuan, B., Lo, K. A., Patterson, H. C., Sun, Y., and Lodish, H. F. (2012). Adiponectin regulates expression of hepatic genes critical for glucose and lipid metabolism. Proc. Natl. Acad. Sci. U.S.A. 109, 14568-14573. doi: 10.1073/pnas. 1211611109

Liu, S. Q., Wang, L. Y., Liu, G. H., Tang, D. Z., Fan, X. X., Zhao, J. P., et al. (2018). Leucine alters immunoglobulin a secretion and inflammatory cytokine expression induced by lipopolysaccharide via the nuclear factor- $\mathrm{\kappa B}$ pathway in intestine of chicken embryos. Animal 22, 1-9.

Liu, J. J., Hezghia, A., Shaikh, S. R., Cenido, J. F., Stark, R. E., Mann, J. J., et al. (2018). Regulation of monoamine transporters and receptors by lipid microdomains: implications for depression. Neuropsychopharmacology 43, 2165-2179. doi: 10.1038/s41386-018-0133-6

Liu, S. Q., Zhao, J. P., Fan, X. X., Liu, G. H., Jiao, H. C., Wang, X. J., et al. (2016). Rapamycin, a specific inhibitor of the target of rapamycin complex 1, disrupts intestinal barrier integrity in broiler chicks. J. Anim. Physiol. Anim. Nutr. 100, 323-330. doi: 10.1111/jpn.12375

Livak, K. J., and Schmittgen, T. D. (2001). Analysis of relative gene expression data using real-time quantitative PCR and the 2(-Delta Delta C(T)) Method. Methods 25, 402-408. doi: 10.1006/meth.2001.1262

Margolis, K. G., Stevanovic, K., Li, Z., Yang, Q. M., Oravecz, T., Zambrowicz, B., et al. (2014). Pharmacological reduction of mucosal but not neuronal serotonin opposes inflammation in mouse intestine. Gut 63, 928-937. doi: 10.1136/ gutjnl-2013-304901

Matsunami, S., Ogura, Y., Amita, H., Izumi, T., Yoshioka, M., and Matsushima, T. (2012). Behavioural and pharmacological effects of fluvoxamine on decisionmaking in food patches and the inter-temporal choices of domestic chicks. Behav. Brain Res. 233, 577-586. doi: 10.1016/j.bbr.2012.05.045

Ministry of Science and Technology (1988a). Regulations for the Administration of Affairs Concerning Experimental Animals Guidelines. New Delhi: Ministry of Science and Technology.

Ministry of Science and Technology (1988b). Guiding Directives for Humane Treatment of Laboratory Animals. New Delhi: Ministry of Science and Technology.

Murray, M. (2000). 5-HTP: The Natural Way to Overcome Depression, Obesity, and Insomnia. New York, NY: Bantam Books.

Namkung, J., Kim, H., and Park, S. (2015). Peripheral serotonin: a new player in systemic energy homeostasis. Mol. Cells 38, 1023-1028. doi: 10.14348/molcells. 2015.0258

Oh, C. M., Namkung, J., Go, Y., Shong, K. E., Kim, K., Kim, H., et al. (2015). Regulation of systemic energy homeostasis by serotonin in adipose tissues. Nat. Commun. 6:6794.

Perianayagam, M. C., Morena, M., Jaber, B. L., and Balakrishnan, V. S. (2005). Anti-oxidants reverse uraemia-induced down-regulation of mitochondrial membrane potential and interleukin-10 production. Eur. J. Clin. Invest. 35, 148-153. doi: 10.1111/j.1365-2362.2005.01462.x

Preidis, G. A., Kim, K. H., and Moore, D. D. (2017). Nutrient-sensing nuclear receptors PPAR $\alpha$ and FXR control liver energy balance. J. Clin. Invest. 127, 1193-1201. doi: $10.1172 /$ jci88893

Regmi, S. C., Park, S. Y., Ku, S. K., and Kim, J. A. (2014). Serotonin regulates innate immune responses of colon epithelial cells through Nox2-derived reactive oxygen species. Free Radic. Biol. Med. 69, 377-389. doi: 10.1016/j. freeradbiomed.2014.02.003 
Sahelian, R. (2000). 5-HTP: Nature's Serotonin Solution. New York, NY: Avery Publishing Group.

Saleh, A. A., Eid, Y. Z., Ebeid, T. A., Ohtsuka, A., Hioki, K., Yamamoto, M., et al. (2012). The modification of the muscle fatty acid profile by dietary supplementation with Aspergillus awamori in broiler chickens. Br. J. Nutr. 108, 1596-1602. doi: 10.1017/s0007114511007069

Saleh, A. A., Hayashi, K., Ijiri, D., and Ohtsuka, A. (2014). Beneficial effects of Aspergillus awamori in broiler nutrition. World's Poult. Sci. J. 70, 857-864. doi: $10.1017 / \mathrm{s} 0043933914000907$

Schaeffer, V., Arbabi, S., Garcia, I. A., Knoll, M. L., Cuschieri, J., Bulger, E. M., et al. (2011). Role of the mTOR pathway in LPS-activated monocytes: influence of hypertonic saline. J. Surg. Res. 171, 769-776. doi: 10.1016/j.jss.2010.05.035

Scheuermann, G. N., Bilgili, S. F., Hess, J. B., and Mulvaney, D. R. (2003). Breast muscle development in commercial broiler chickens. Poult. Sci. 82, 1648-1658. doi: $10.1093 / \mathrm{ps} / 82.10 .1648$

Schoonjans, K., Staels, B., and Auwerx, J. (1996). Role of the peroxisome proliferator-activated receptor (PPAR) in mediating the effects of fibrates and fatty acids on gene expression. J. Lipid Res. 37, 907-925.

Sharma, A., Castellani, R. J., Smith, M. A., Muresanu, D. F., Dey, P. K., and Sharma, H. S. (2019). 5-Hydroxytryptophan: a precursor of serotonin influences regional blood-brain barrier breakdown, cerebral blood flow, brain edema formation, and neuropathology. Int. Rev. Neurobiol. 146, 1-44. doi: 10.1016/bs.irn.2019. 06.005

Sloley, B. D., and Juorio, A. V. (1995). Monoamine neurotransmitters in invertebrates and vertebrates: an examination of the diverse enzymatic pathways utilized to synthesize and inactivate biogenic amines. Int. Rev. Neurobiol. 38, 253-303. doi: 10.1016/s0074-7742(08)60528-0

Steffens, S. M., Casas, D. C., Milanez, B. C., Freitas, C. G., Paschoalini, M. A., and Marino-Neto, J. (1997). Hypophagic and dipsogenic effects of central 5-HT injections in pigeons. Brain Res. Bull. 44, 681-688. doi: 10.1016/s0361-9230(97) 00199-8

Sun, E. W. L., Martin, A. M., Young, R. L., and Keating, D. J. (2019). The regulation of peripheral metabolism by gut-derived hormones. Front. Endocrinol. 9:754. doi: $10.3389 /$ fendo. 2018.00754

Tang, D., Wu, J., Jiao, H., Wang, X., Zhao, J., and Lin, H. (2019). The development of antioxidant system in the intestinal tract of broiler chickens. Poult. Sci. 98 , 664-678. doi: 10.3382/ps/pey415

Tecott, L. H. (2007). Serotonin and the orchestration of energy balance. Cell Metab. 6, 352-361. doi: 10.1016/j.cmet.2007.09.012

van der Eijk, J. A. J., Rodenburg, T. B., de Vries, H., Kjaer, J. B., Smidt, H., Naguib, M., et al. (2020). Early-life microbiota transplantation affects behavioural responses, serotonin and immune characteristics in chicken lines divergently selected on feather pecking. Sci. Rep. 10:2750.

Veenstra-VanderWeele, J., Anderson, G. M., and Cook, E. H. Jr. (2000). Pharmacogenetics and the serotonin system: initial studies and future directions. Eur. J. Pharmacol. 410, 165-181. doi: 10.1016/s0014-2999(00) 00814- 1
Walther, D. J., Peter, J. U., Bashammakh, S., Hörtnagl, H., Voits, M., Fink, H., et al. (2003). Synthesis of serotonin by a second tryptophan hydroxylase isoform. Science 299:76. doi: 10.1126/science.1078197

Wang, H., and Eckel, R. H. (2009). Lipoprotein lipase: from gene to obesity. Am. J. Physiol. Endocrinol. Metab. 297, 271-288.

Wang, L., Gui, Y. S., Tian, X. L., Cai, B. Q., Wang, D. T., Zhang, D., et al. (2011). Inactivation of mammalian target of rapamycin (mTOR) by rapamycin in a murine model of lipopolysaccharide-induced acute lung injury. Chin. Med. J. $124,3112-3117$.

Watanabe, H., Akasaka, D., Ogasawara, H., Sato, K., Miyake, M., Saito, K., et al. (2010). Peripheral serotonin enhances lipid metabolism by accelerating bile acid turnover. Endocrinology 151, 4776-4786. doi: 10.1210/en.2009-1349

Watanabe, H., Kobayashi, K., and Isayama, Y. (1975). Peculiar secretory IgA system identified in chickens. II. Identification and distribution of free secretory component and immunoglobulins of IgA, IgM, and IgG in chicken external secretions. J. Immunol. 115, 998-1001.

Yassin, H., Velthuis, A. G. J., Boerjan, M., and van Riel, J. (2009). Field study on broilers' first-week mortality. Poult. Sci. 88, 798-804. doi: 10.3382/ps.200800292

Yerpes, M., Llonch, P., and Manteca, X. (2020). Factors associated with cumulative first-week mortality in broiler chicks. Animals 10:E310. doi: 10. 3390/ani10020310

Yue, Y., Guo, Y., and Yang, Y. (2017). Effects of dietary L-tryptophan supplementation on intestinal response to chronic unpredictable stress in broilers. Amino Acids 49, 1227-1236. doi: 10.1007/s00726-017-2424-3

Zendehdel, M., Sardari, F., Hassanpour, S., Rahnema, M., Adeli, A., and Ghashghayi, E. (2017). Serotonin-induced hypophagia is mediated via $\alpha 2$ and $\beta 2$ adrenergic receptors in neonatal layer-type chickens. Br. Poult. Sci. 58, 298-304. doi: 10.1080/00071668.2017.1278626

Zhao, J. P., Jiao, H. C., Jiang, Y. B., Song, Z. G., Wang, X. J., and Lin, H. (2012). Cool perch availability improves the performance and welfare status of broiler chickens in hot weather. Poult. Sci. 91, 1775-1784. doi: 10.3382/ps.2011-02058

Zhou, H., Song, X., Briggs, M., Violand, B., Salsgiver, W., Gulve, E. A., et al. (2005). Adiponectin represses gluconeogenesis independent of insulin in hepatocytes. Biochem. Biophys. Res. Commun. 338, 793-799. doi: 10.1016/j.bbrc.2005.10.007

Conflict of Interest: The authors declare that the research was conducted in the absence of any commercial or financial relationships that could be construed as a potential conflict of interest.

Copyright (c) 2020 Wang, Liu, Li, Wang, Wang, Zhao, Jiao and Lin. This is an open-access article distributed under the terms of the Creative Commons Attribution License (CC BY). The use, distribution or reproduction in other forums is permitted, provided the original author(s) and the copyright owner(s) are credited and that the original publication in this journal is cited, in accordance with accepted academic practice. No use, distribution or reproduction is permitted which does not comply with these terms. 